\title{
Prevalence of Self-Reported Diabetes and Its Associated Factors: A Population-Based Study in Brazil
}

\author{
Fabiana A. F. Da-Mata, ${ }^{1}$ Tais F. Galvao, ${ }^{2}$ Mauricio G. Pereira, ${ }^{1}$ and Marcus T. Silva ${ }^{3}$ \\ ${ }^{1}$ Faculty of Medicine, University of Brasilia, Campus Universitario, Conjunto 16, Sala 77, 70904-970 Brasilia, DF, Brazil \\ ${ }^{2}$ Getulio Vargas University Hospital, Federal University of Amazonas, Rua Apurina, 4 Praça 14, 69020-170 Manaus, AM, Brazil \\ ${ }^{3}$ Faculty of Medicine, Federal University of Amazonas, Rua Afonso Pena 1053 Centro, 69020-160 Manaus, AM, Brazil \\ Correspondence should be addressed to Fabiana A. F. Da-Mata; fagfigueiredo@hotmail.com
}

Received 18 September 2014; Revised 10 December 2014; Accepted 10 December 2014

Academic Editor: Nikolaos Papanas

\begin{abstract}
Copyright (C) 2015 Fabiana A. F. Da-Mata et al. This is an open access article distributed under the Creative Commons Attribution License, which permits unrestricted use, distribution, and reproduction in any medium, provided the original work is properly cited.
\end{abstract}

\begin{abstract}
Aim. The aim of this study was to estimate the prevalence of diabetes and its associated risk factors in adults from Brasilia, Brazil. Methods. The present cross-sectional population-based study consisted of interviews with individuals aged 18-65 years. Participants were selected through two-stage probability sampling by clusters and stratified by sex and age. Demographic and clinical data were collected directly with participants from February to May 2012. Self-reported diabetes prevalence was calculated at a 95\% confidence interval (CI). Prevalence ratios (PR) were adjusted by Poisson regression with robust variance. Results. In all, 1,820 individuals were interviewed. Diabetes prevalence in the adult population of Brasilia was 10.1\% (95\% CI, 8.5\%-11.6\%). Variables associated with diabetes were an age between 35 and 49 years ( $P R=1.83$; 95\% CI, 1.19-2.82) or 50 and 65 years ( $P R=1.95$; 95\% CI, 1.17-3.23), hypertension $(\mathrm{PR}=4.04 ; 95 \% \mathrm{CI}, 2.66-6.13)$, respiratory disease $(\mathrm{PR}=1.67 ; 95 \% \mathrm{CI}, 1.11-2.50)$, cardiovascular disease $(\mathrm{PR}=1.74$; $95 \% \mathrm{CI}, 1.15-2.63)$, and pain/discomfort ( $\mathrm{PR}=1.71 ; 95 \% \mathrm{CI}, 1.21-2.41)$. Conclusion. Diabetes is a prevalent condition in adults living in Brasilia, and disease risk increases with age and comorbidities. Future health policies should focus on screening programs and prevention for the more vulnerable groups.
\end{abstract}

\section{Introduction}

Diabetes mellitus is a global health problem and an important cause of mortality and morbidity in many countries. Its prevalence in adults has been increasing worldwide over the last 30 years [1]. It is estimated that diabetes will affect 366 million individuals worldwide by 2030 [2]. The trend of increasing diabetes prevalence seems to prevail among developing countries. In Brazil, diabetes affected 11.3 million people in 2011, and this number is likely to triple by 2030 [3]. Estimates suggest that the diabetes rate in less developed countries will increase by $69 \%$ between 2010 and 2030 [4].

Diabetes imposes a burden for society such as high socioeconomic costs that have an impact on productivity as well as life and health quality [5]. This situation seems to be worse in developing countries, where the healthcare system often fails to meet demand [6]. Studies have concluded that a Western dietary pattern, sedentary lifestyle, and genetic factors play a central role in diabetes development [7].

The Brazilian Ministry of Health has followed the World Health Organization's recommendations and has taken some actions to monitor diabetes such as an annual telephonebased survey [8]. Socioeconomic disparities might contribute to some degree of heterogeneity in measures of prevalence between regions [9]. A study demonstrated that diabetes prevalence across the Brazilian states ranged from $11 \%$ to $25 \%$, with an overall rate of $16 \%$ in 2001 [10].

Brasilia, the capital of Brazil, is located in the CentralWest region of the country. The city has the highest Human Development Index in Brazil, but it has one of the highest levels of social inequality compared with other Brazilian regions $[11,12]$. These characteristics of Brasilia warrant further investigation in many aspects, including the health status of its population. 
Thus, the goal of this study was to estimate the prevalence of diabetes and its associated risk factors in adults of Brasilia, Brazil.

\section{Materials and Methods}

2.1. Study Design and Settings. The present cross-sectional population-based study was conducted in Brasilia, Brazil, from February to May 2012. The target population was $1,702,419$ inhabitants aged $18-65$ years [12].

2.2. Sample Size and Participants. The sample size was calculated based on an estimation of $16 \%$ of self-reported diabetes cases [10]. Considering a 95\% confidence interval (CI), precision of $2.25 \%$, and a design effect of 1.8 , the estimated sample size was 1,835 individuals. We added $10 \%$ of the sample size to compensate for any eventual attrition, which resulted in a final sample of 2,019 individuals.

Participants were selected by a two-stage probability sampling process by cluster and were stratified by sex and age. A total of 220 census tracts were randomly selected from 3,886 urban tracts with more than 200 inhabitants [12]. Up to 10 households were selected from each census tract. In total, one adult per household was selected following the predefined quotas of sex and age to answer the interview. Trained professionals surveyed all of the participants in their homes using a semistructured questionnaire. To ensure reliability, $20 \%$ of the interviews were audited by telephone. To test the understanding and acceptability of the questionnaire, 150 pilot interviews were held prior to data collection.

2.3. Study Variables. The dependent variable was self-reported diabetes. Independent variables included demographic characteristics (age group, sex, marital status, living arrangements, and household location), socioeconomic characteristics (level of education, occupation, and social class), chronic health conditions (self-reported hypertension, depression, respiratory diseases, cardiovascular diseases, and other chronic diseases), access to healthcare (health insurance, medical consultation, and hospitalization), and perceived health status (mobility, self-care, usual activities, pain/ discomfort, and anxiety/depression) [13]. The stratification was based on the Brazilian criterion of economic classification, which defines five classes, with "A" being the wealthiest group and "E" being the poorest [14].

2.4. Statistical Analysis. In all of the analyses, the effects of complex sampling were considered. First, we described participant characteristics by weighted frequencies. Self-reported diabetes prevalence in the population was then calculated at a $95 \%$ CI. To identify factors related to diabetes prevalence, we calculated prevalence ratios (PR) using bivariate analysis and calculated the adjusted PR by a Poisson regression model with robust variance [15]. In this model, all of the variables were analyzed simultaneously. We preferred to use this more conservative model that included all of the variables to allow for better confounding adjustment. Other models that included only the most significant variables were tested and

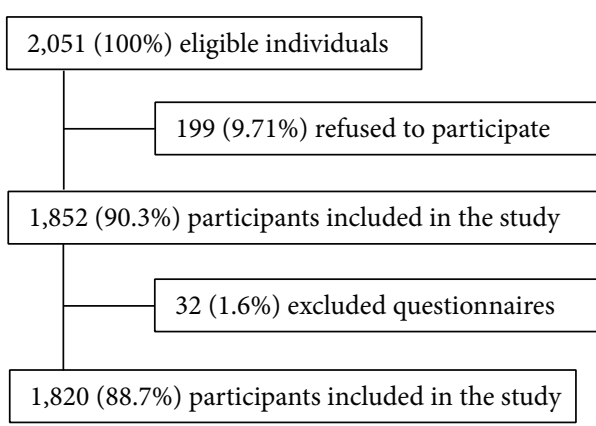

FIGURE 1: Sample selection.

did not change the significance of the variables. Associations were considered to be statistically significant when $P<0.05$. The STATA software version 10.1 was used for all of the calculations [16].

2.5. Ethics Statement. This study was approved by the University of Brasilia Ethics Committee. All participants signed a term of free and informed consent.

\section{Results}

3.1. Participants and Sample Characteristics. In total, 1,820 individuals were included in the study (Figure 1). The main characteristics of the sample are shown in Table 1. Approximately $60 \%$ of the participants were women, and $57 \%$ were aged between 35 and 60 years. Most of the participants belonged to economic class "C," had completed high school, were married or cohabitating, lived with at least one more person in the household, and dwelled in a satellite town.

3.2. Diabetes and Correlates. Diabetes was self-reported by $10.1 \%$ (95\% CI: 8.5\%-11.6\%) of the adult population in Brasilia. Table 1 depicts diabetes prevalence and prevalence ratios (PR) before and after adjustment by Poisson regression.

The age group of 35-65 years, hypertension, respiratory disease, cardiovascular disease, and pain/discomfort were significantly associated with diabetes. Sex, marital status, living arrangements, social class, education level, employability, living location, health insurance, medical consultation, hospitalization, physical mobility, self-care, usual activities, and anxiety/depression revealed no significant association.

Figure 2 illustrates differences in diabetes prevalence between all persons and the population with comorbidities. Diabetes prevalence in the age range 30-65 years is higher among individuals with cardiovascular disease, followed by those with hypertension and those with respiratory diseases. This result suggests that the likelihood of diabetes increases with age and is greater in persons with comorbidities.

\section{Discussion}

Diabetes was self-reported by one of every ten Brazilian adults. An age of 35 years and over, presence of pain or discomfort, cardiovascular disease, hypertension, and respiratory 
TABLE 1: Sociodemographics of the sample population, diabetes prevalence, and unadjusted and adjusted prevalence ratios $(\mathrm{PR})(\mathrm{N}=1,820)$.

\begin{tabular}{|c|c|c|c|c|c|c|c|}
\hline Variables & $\begin{array}{c}\text { Frequency } \\
\text { distribution (\%) }\end{array}$ & $\begin{array}{c}\text { Diabetes } \\
\text { prevalence (\%) }\end{array}$ & Unadjusted PR & $P$ value & Adjusted PR & $95 \% \mathrm{CI}$ & $P$ value \\
\hline \multicolumn{8}{|l|}{ Sex } \\
\hline Male & 40.7 & 9.6 & 1.00 & - & 1.00 & - & - \\
\hline Female & 59.3 & 10.4 & 1.08 & 0.641 & 0.89 & $0.65-1.23$ & 0.489 \\
\hline \multicolumn{8}{|l|}{ Age group (years) } \\
\hline $18-34$ & 43.5 & 4.5 & 1.00 & - & 1.00 & - & - \\
\hline $35-49$ & 35.1 & 11.3 & 2.52 & $<0.001$ & 1.83 & $1.19-2.82$ & 0.006 \\
\hline $50-65$ & 21.4 & 19.0 & 4.24 & $<0.001$ & 1.95 & $1.17-3.23$ & 0.010 \\
\hline \multicolumn{8}{|l|}{ Marital status } \\
\hline Single & 47.8 & 7.9 & 1.00 & - & 1.00 & - & - \\
\hline Married/cohabitating & 52.2 & 12.0 & 1.52 & 0.014 & 1.61 & $1.16-2.72$ & 0.005 \\
\hline \multicolumn{8}{|l|}{ Living arrangements } \\
\hline At least with one person & 94.5 & 10.2 & 1.00 & - & 1.00 & - & - \\
\hline Alone & 5.5 & 8.1 & 0.79 & 0.529 & 1.02 & $0.49-2.12$ & 0.954 \\
\hline \multicolumn{8}{|l|}{ Social class } \\
\hline Class A & 8.5 & 7.6 & 1.00 & - & 1.00 & - & - \\
\hline Class B & 34.4 & 10.1 & 1.33 & 0.373 & 1.72 & $0.83-3.65$ & 0.145 \\
\hline Class C & 47.5 & 10.8 & 1.42 & 0.257 & 1.47 & $0.67-3.22$ & 0.331 \\
\hline Classes D-E & 9.5 & 8.6 & 1.14 & 0.750 & 1.21 & $0.45-3.24$ & 0.709 \\
\hline \multicolumn{8}{|l|}{ Level of education } \\
\hline College or higher & 17.4 & 8.5 & 1.00 & - & 1.00 & - & - \\
\hline High school & 34.4 & 8.0 & 0.95 & 0.833 & 0.91 & $0.54-1.52$ & 0.715 \\
\hline Primary school & 21.6 & 9.3 & 1.10 & 0.738 & 1.19 & $0.65-2.16$ & 0.567 \\
\hline Incomplete primary school & 26.6 & 14.5 & 1.72 & 0.034 & 1.07 & $0.58-2.00$ & 0.826 \\
\hline \multicolumn{8}{|l|}{ Occupation } \\
\hline Employed & 45.6 & 8.3 & 1.00 & - & 1.00 & - & - \\
\hline Unemployed or retired $^{\mathrm{a}}$ & 54.4 & 11.6 & 1.40 & 0.055 & 0.97 & $0.70-1.35$ & 0.877 \\
\hline \multicolumn{8}{|l|}{ Location } \\
\hline Downtown & 17.2 & 8.0 & 1.00 & - & 1.00 & - & - \\
\hline Satellite towns & 82.8 & 10.5 & 1.31 & 0.284 & 0.98 & $0.53-1.79$ & 0.937 \\
\hline \multicolumn{8}{|l|}{ Self-reported chronic conditions } \\
\hline Hypertension & 21.5 & 29.9 & 6.43 & $<0.001$ & 4.04 & $2.66-6.13$ & $<0.001$ \\
\hline Respiratory disease & 7.3 & 20.9 & 2.37 & $<0.001$ & 1.67 & $1.11-2.50$ & 0.013 \\
\hline Cardiovascular disease & 6.9 & 36.5 & 4.74 & $<0.001$ & 1.74 & $1.15-2.63$ & 0.009 \\
\hline Other chronic diseases & 8.0 & 10.6 & 1.05 & 0.828 & 0.54 & $0.29-1.01$ & 0.052 \\
\hline \multicolumn{8}{|l|}{ Healthcare services } \\
\hline No health insurance & 72.3 & 9.5 & 0.83 & 0.311 & 0.84 & $0.59-1.20$ & 0.339 \\
\hline Medical consultation & 42.5 & 12.8 & 1.66 & $<0.001$ & 0.94 & $0.70-1.27$ & 0.690 \\
\hline Hospitalization & 9.9 & 16.6 & 1.80 & 0.005 & 1.43 & $0.98-2.10$ & 0.062 \\
\hline \multicolumn{8}{|l|}{ Perceived health status } \\
\hline Mobility & 7.9 & 19.7 & 2.15 & $<0.001$ & 1.29 & $0.84-2.00$ & 0.242 \\
\hline Self-care & 4.0 & 17.7 & 1.83 & 0.045 & 0.75 & $0.35-1.63$ & 0.471 \\
\hline Usual activities & 6.9 & 16.2 & 1.68 & 0.042 & 0.98 & $0.54-1.78$ & 0.941 \\
\hline Pain/discomfort & 37.0 & 15.7 & 2.30 & $<0.001$ & 1.71 & $1.21-2.41$ & 0.002 \\
\hline Anxiety/depression & 23.0 & 14.8 & 1.70 & 0.001 & 1.06 & $0.70-1.63$ & 0.777 \\
\hline
\end{tabular}

Note: ${ }^{a}$ included students not formally employed.

CI: confidence interval. 


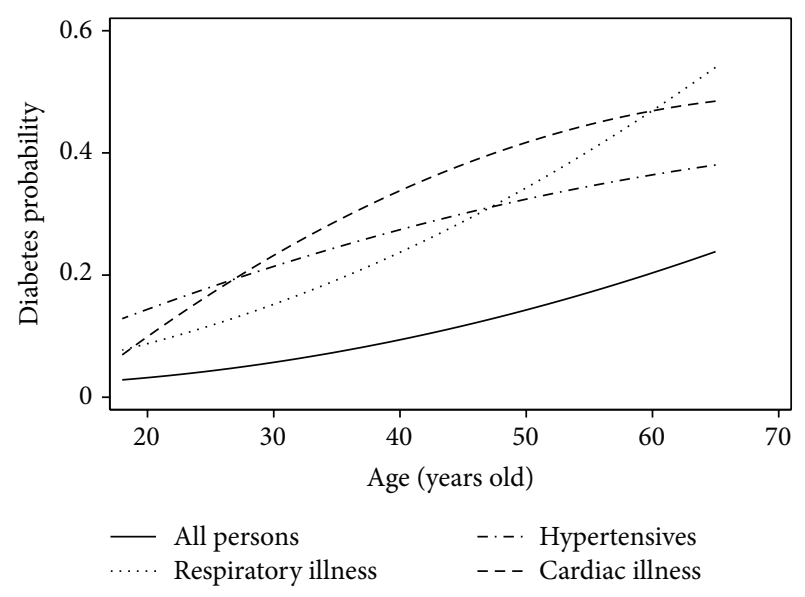

FIGURE 2: Diabetes prevalence by age in groups with different health conditions.

disease were positively associated with diabetes in the adult population of Brasilia.

The main limitations of our study were the self-reported assessments of the primary outcome and independent variables. Self-reported diabetes might be a source of bias because individuals need to be aware of the diagnosis prior to answering, which could result in disease underestimation [1]. However, performing a clinical test for diagnosing diabetes is not always possible in population-based studies. Thus, selfreported answers regarding diabetes have been a common practice according to the literature $[17,18]$. Another shortcoming was the cross-sectional design of the study, which hampers a causal relationship between diabetes and the significantly associated factors identified herein.

A previous population-based study developed in Brazil in 2008 used telephone interviews to investigate self-reported diabetes prevalence and found low prevalence rates in Brasilia [19]. Another study found that Brasilia was the region with the highest diabetes prevalence compared with other Brazilian regions from 2002 to 2007 [20]. Research identified a significant increase in self-reported diabetes in the Brazilian population because it ascended from $3.3 \%$ in 1998 to $5.3 \%$ in 2008 [3]. In South and Central America, the estimated diabetes prevalence in 2013 was $8.0 \%$; Brazil demonstrated the highest prevalence, followed by Colombia and Argentina [21]. The variability of diabetes prevalence may be due to a poorer diet and a lack of physical activity, or it could be related to better access to diagnostic testing [3].

As expected, our results demonstrated that the likelihood of having diabetes increases with age. From a healthcare policy perspective, diabetes prevention and management programs should target young people and not only the elderly population.

Diabetes prevalence was higher among individuals with cardiovascular disease, hypertension, and respiratory disease compared with the general population. There is convincing evidence of the association between diabetes and hypertension, which increases the risk of a cardiovascular event [22]. A 2003 study conducted in São Luis, a city located in one of the poorest areas of Brazil, observed a positive association between diabetes and hypertension [23]. A cross-sectional study conducted between 2004 and 2005 in São Jose do Rio Preto, a city in the Brazilian southeast region, revealed that the diabetes prevalence was almost threefold higher in a population of hypertensive individuals compared with the general population [9].

A cohort study performed in women between 1988 and 1996 throughout 11 states in the United States found that chronic obstructive pulmonary disease was a diabetes risk factor [24]. A retrospective cohort study conducted in northern California reported that individuals with diabetes are at a greater risk of developing asthma, chronic obstructive pulmonary disease, fibrosis, and pneumonia [25].

Socioeconomic factors were not associated with diabetes in our sample. In contrast, a systematic review of 10 studies suggests that growing up in a socioeconomically disadvantaged environment may contribute to diabetes in later life [26]. An Australian study also described a positive association between socioeconomic variables and diabetes in adults aged 45 years and over [27].

The perceived health dimensions physical mobility, selfcare, usual activities, and anxiety/depression were not associated with diabetes in our sample. In 2012, a literature review found that diabetes was considered a potential risk factor for the poor performance of daily life activities among individuals aged 50 years and over [28]. A study conducted with older adult New York residents observed that self-reported diabetes was not associated with depression [29]. Other than depression, this finding might depict an association between diabetes and activities of daily living, which may be developed at older ages.

\section{Conclusion}

Diabetes is a common health condition in adults living in Brasilia and is positively associated with older age, cardiovascular disease, hypertension, respiratory disease, and presence of pain or discomfort. Preventive strategies should prioritize populations with at least one of the identified factors.

\section{Conflict of Interests}

The authors declare that they have no conflict of interests.

\section{Acknowledgments}

This research was partially supported by the Brazilian National Research Council, CNPq, Grant no. 564831/2010-7, and by the Foundation for Supporting Research in the State of Amazonas, FAPEAM, Grant no. 062.00848/2014.

\section{References}

[1] A. Rubinstein, L. Gutierrez, A. Beratarrechea, and V. E. Irazola, "Increased prevalence of diabetes in Argentina is due to easier health care access rather than to an actual increase in prevalence," PLoS ONE, vol. 9, no. 4, Article ID e92245, 2014. 
[2] S. Wild, G. Roglic, A. Green, R. Sicree, and H. King, "Global prevalence of diabetes: estimates for the year 2000 and projections for 2030," Diabetes Care, vol. 27, no. 5, pp. 1047-1053, 2004.

[3] M. I. Schmidt, B. B. Duncan, G. A. E Silva et al., "Chronic non-communicable diseases in Brazil: burden and current challenges," The Lancet, vol. 377, no. 9781, pp. 1949-1961, 2011.

[4] J. E. Shaw, R. A. Sicree, and P. Z. Zimmet, "Global estimates of the prevalence of diabetes for 2010 and 2030," Diabetes Research and Clinical Practice, vol. 87, no. 1, pp. 4-14, 2010.

[5] P. L. Bosi, A. M. Carvalho, D. Contrera et al., "Prevalência de diabetes melito e tolerância à glicose diminuída na população urbana de 30 a 79 anos da cidade de São Carlos, São Paulo," Arquivos Brasileiros de Endocrinologia \& Metabologia, vol. 53, no. 6, pp. 726-732, 2009.

[6] N. Almeida-Filho, "Higher education and health care in Brazil," The Lancet, vol. 377, no. 9781, pp. 1898-1900, 2011.

[7] O. Garcia-Dominic, E. J. Lengerich, F. Camacho et al., "Prevalence of diabetes and associated obesity in Pennsylvania adults, 1995-2010," Preventing Chronic Disease, vol. 11, Article ID 130330, 2014.

[8] B. P. M. Iser, R. M. Claro, E. C. de Moura, D. C. Malta, and O. L. M. Neto, "Risk and protection factors for chronic non communicable diseases by telephone survey_VIGITEL Brazil-2009," Revista Brasileira de Epidemiologia, vol. 14, supplement 1, pp. 90-102, 2011.

[9] J. P. Cipullo, J. F. V. Martin, L. A. D. S. Ciorlia et al., "Hypertension prevalence and risk factors in a Brazilian urban population," Arquivos Brasileiros de Cardiologia, vol. 94, no. 4, pp. 519-526, 2010.

[10] L. B. Nucci, C. M. Toscano, A. L. M. Maia et al., "A nationwide population screening program for diabetes in Brazil," Revista Panamericana de Salud Publica, vol. 16, no. 5, pp. 320-327, 2004.

[11] "Programa das Nações Unidas para o Desenvolvimento. Atlas do Desenvolvimento Humano no Brasil 2013," 2014, http://atlasbrasil.org.br/2013/ranking.

[12] "IBGE- Instituto Brasileiro de Geografiae estatística. Censo Demográfico 2010," 2014, http://www.ibge.gov.br/home/estatistica/populacao/censo2010/default.shtm.

[13] R. Rabin and F. De Charro, "EQ-5D: a measure of health status from the EuroQol Group," Annals of Medicine, vol. 33, no. 5, pp. 337-343, 2001.

[14] CCEB, "Associação Brasileira de Empresas de Pesquisa. Critério de Classificação Econômica Brasil. 2012," August 2013, http:// www.abep.org/novo/Content.aspx?ContentID=139.

[15] J. Lee, S. T. Chuen, and S. C. Kee, "A practical guide for multivariate analysis of dichotomous outcomes," Annals of the Academy of Medicine Singapore, vol. 38, no. 8, pp. 714-719, 2009.

[16] A. B. Siller and L. Tompkins, "The big four: analyzing complex sample survey data using SAS, SPSS, STATA, and SUDAAN," Tech. Rep. Paper 172-31, 2005.

[17] L. A. B. de Almeida, F. J. G. Pitanga, M. M. Freitas, C. P. S. Pitanga, E. H. M. Dantas, and C. C. Beck, "Caloric expenditure of different domains of physical activity as predictors of the absence of diabetes in adults," Revista Brasileira de Medicina do Esporte, vol. 18, no. 1, pp. 17-21, 2012.

[18] T. Borges, A. J. Rombaldi, L. Q. Corrêa, A. G. Knuth, and P. C. Hallal, "Prevalência de autorrelato da morbidade e conhecimento sobre diabetes: estudo populacional de uma cidade no sul do Brasil," Revista Brasileira de Cineantropometria e Desempenho Humano, vol. 14, no. 5, pp. 560-570, 2012.
[19] Brasil Ministério da Saúde, Secretaria de Vigilância em Saúde, and Secretaria de Gestão Estratégica e Participativa, Vigitel Brasil 2008: vigilância de fatores de risco e proteção para doenças crônicas por inquérito telefônico, Ministério da Saúde, 2009.

[20] J. C. R. Dias and J. A. D. B. Campos, "Diabetes mellitus: razão de prevalências nas diferentes regiões geográficas no Brasil, 20022007," Ciência \& Saúde Coletiva, vol. 17, no. 1, pp. 239-244, 2012.

[21] International Diabetes Federation, Diabetes Atlas, IDF, 6th edition, 2013.

[22] S. M. Grundy, I. J. Benjamin, G. L. Burke et al., "Diabetes and cardiovascular disease: a statement for healthcare professionals from the american heart association," Circulation, vol. 100, no. 10, pp. 1134-1146, 1999.

[23] J. B. Barbosa, A. A. M. da Silva, A. M. dos Santos et al., "Prevalência da hipertensão arterial em adultos e fatores associados em São Luís-MA," Arquivos Brasileiros de Cardiologia, vol. 91, no. 4, pp. 260-266, 2008.

[24] J. S. Rana, M. A. Mittleman, J. Sheikh et al., "Chronic obstructive pulmonary disease, asthma, and risk of type 2 diabetes in women," Diabetes Care, vol. 27, no. 10, pp. 2478-2484, 2004.

[25] S. F. Ehrlich, C. P. Quesenberry Jr., S. K. van den Eeden, J. Shan, and A. Ferrara, "Patients diagnosed with diabetes are at increased risk for asthma, chronic obstructive pulmonary disease, pulmonary fibrosis, and pneumonia but not lung cancer," Diabetes Care, vol. 33, no. 1, pp. 55-60, 2010.

[26] T. Tamayo, H. Christian, and W. Rathmann, "Impact of early psychosocial factors (childhood socioeconomic factors and adversities) on future risk of type 2 diabetes, metabolic disturbances and obesity: a systematic review," BMC Public Health, vol. 10, article 525, 2010.

[27] S. M. Shamshirgaran, L. Jorm, H. Bambrick, and A. Hennessy, "Independent roles of country of birth and socioeconomic status in the occurrence of type 2 diabetes," BMC Public Health, vol. 13, no. 1, article 1223, 2013.

[28] J. Petrofsky, L. Berk, and H. Al-Nakhli, “The influence of autonomic dysfunction associated with aging and type 2 diabetes on daily life activities," Experimental Diabetes Research, vol. 2012, Article ID 657103, 12 pages, 2012.

[29] P. Palta, S. H. Golden, J. A. Teresi et al., "Depression is not associated with diabetes control in minority elderly," Journal of Diabetes and Its Complications, vol. 28, no. 6, pp. 798-804, 2014. 


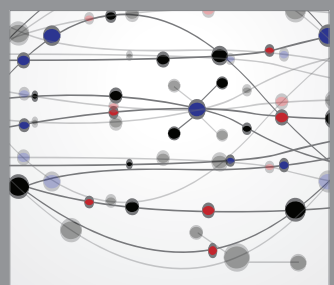

The Scientific World Journal
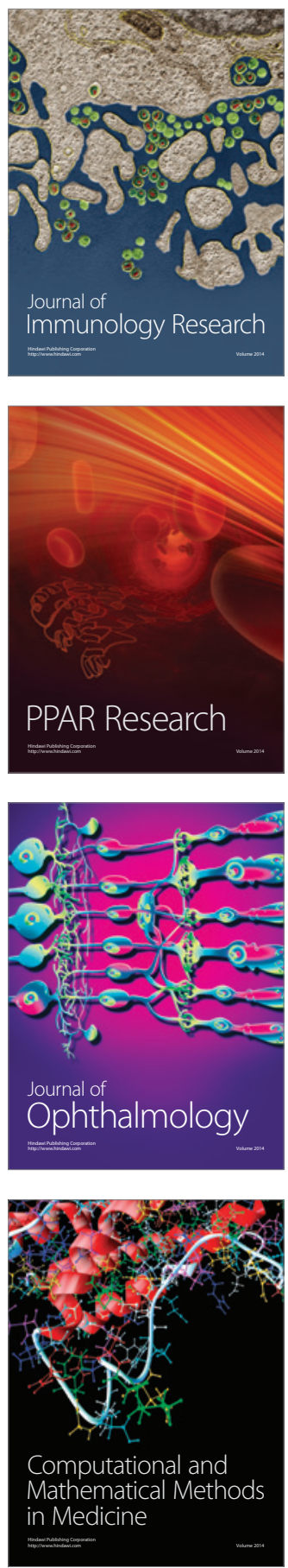

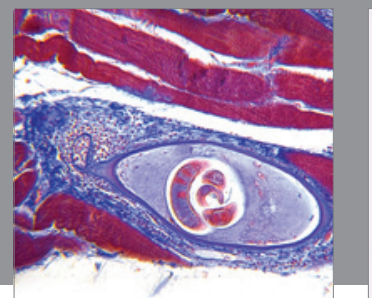

Gastroenterology

Research and Practice
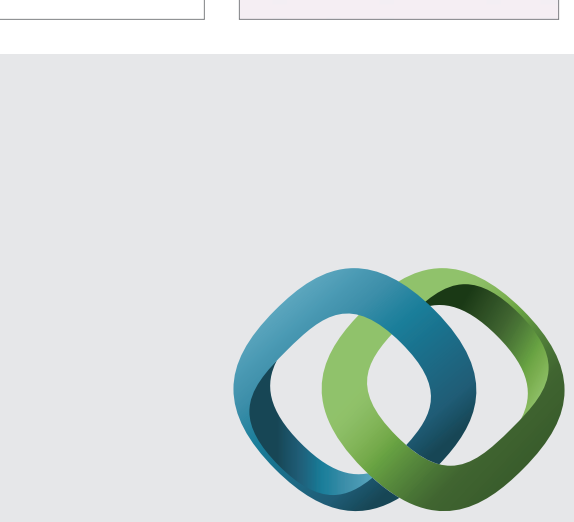

\section{Hindawi}

Submit your manuscripts at

http://www.hindawi.com
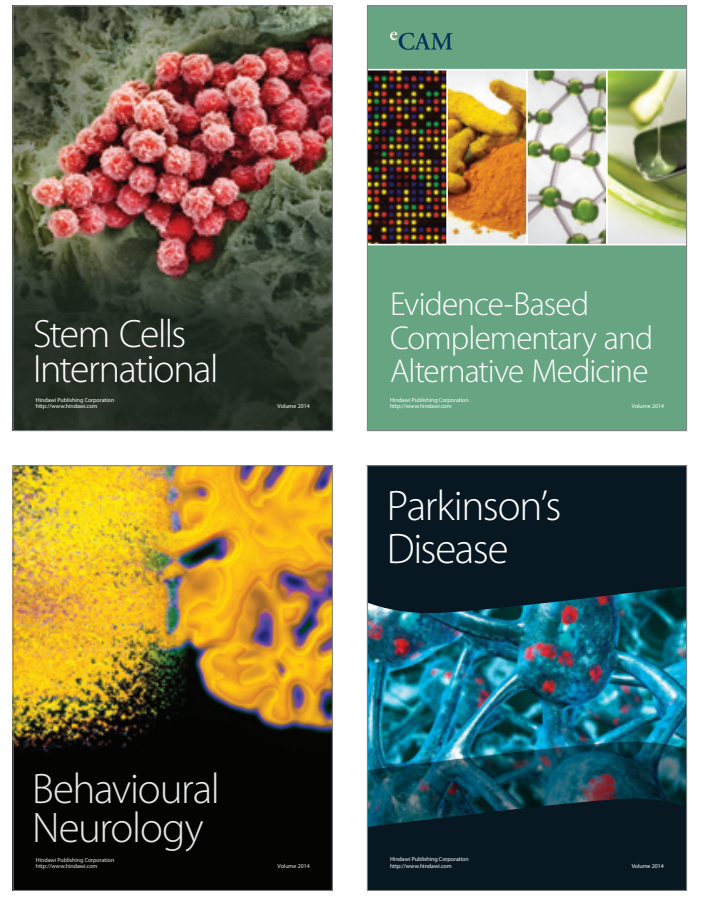
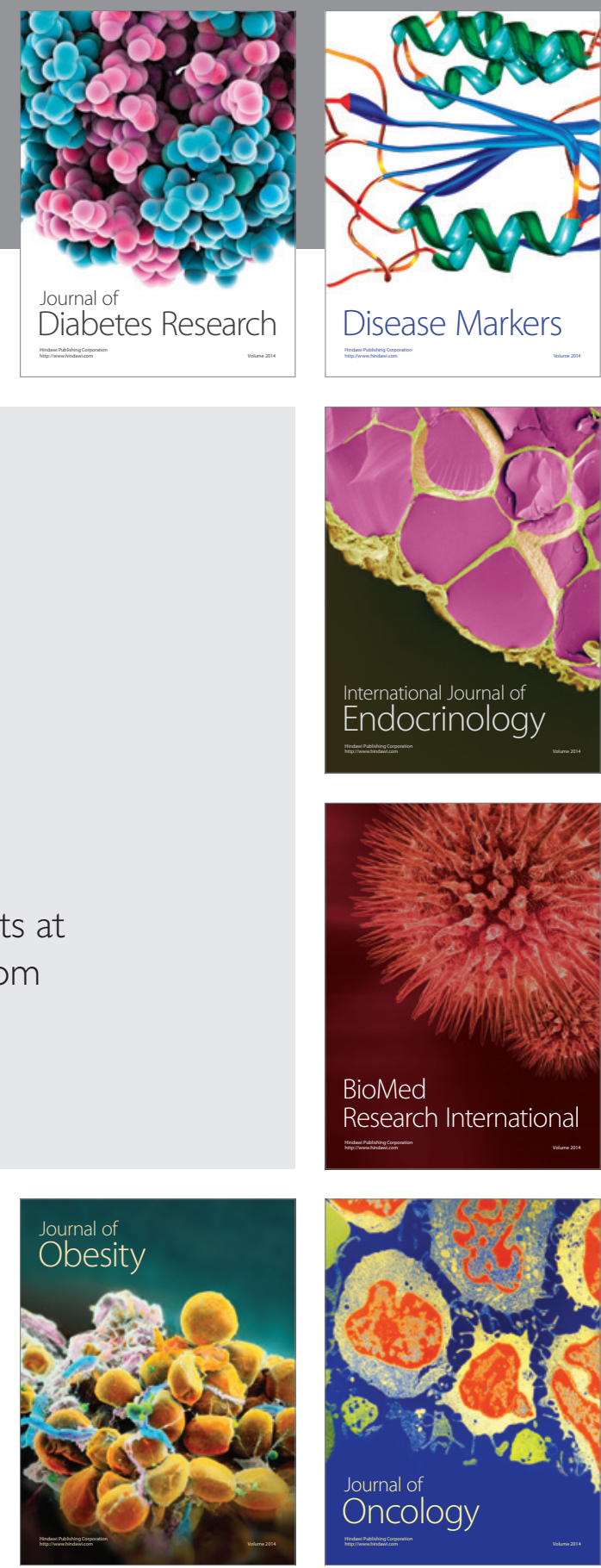

Disease Markers
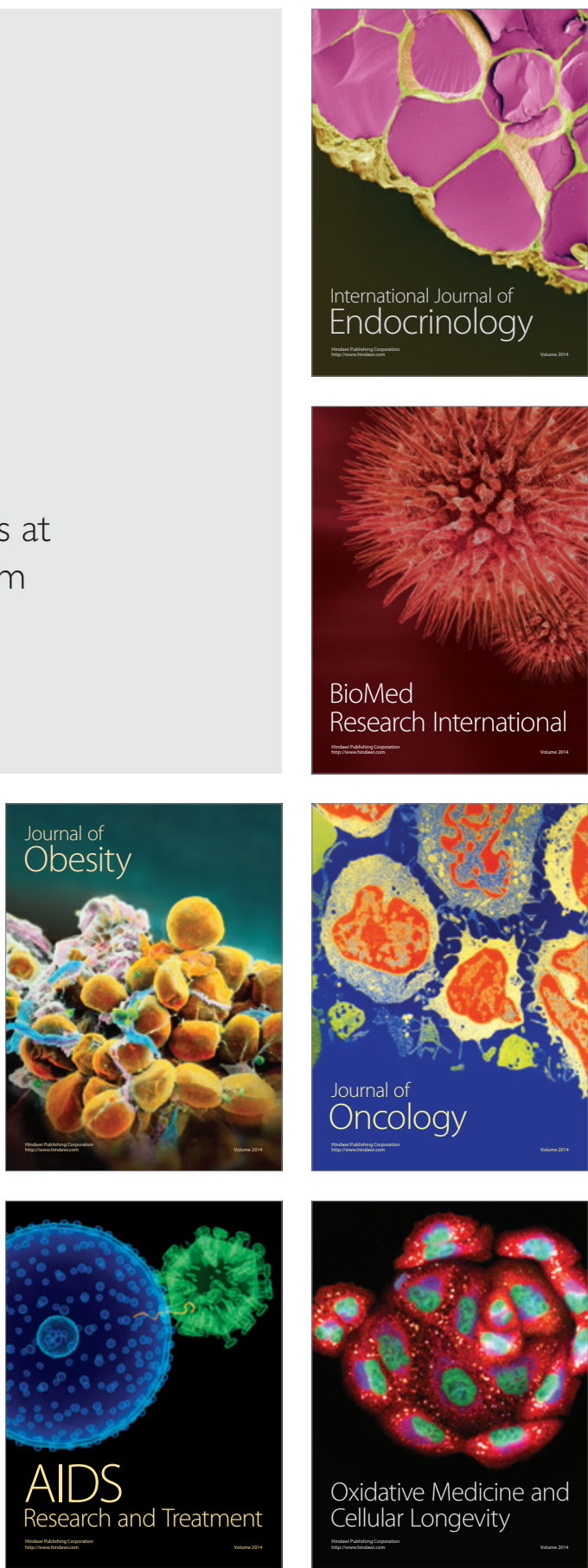